\title{
Role of myocardial perfusion scintigraphy in octogenarians: Time for reappraisal?
}

\author{
Thomas H. Schindler, $M D^{a}$ \\ a Division of Nuclear Medicine, Mallinckrodt Institute of Radiology, Washington University \\ School of Medicine, St. Louis, MO
}

Received Nov 27, 2017; accepted Nov 27, 2017

doi:10.1007/s12350-017-1162-y

\section{See related article, pp.1342-1349}

Nudi et al. ${ }^{1}$ should be congratulated for their work to appraise the use of myocardial perfusion scintigraphy (MPS) for prognostication in octogenarians. The authors performed a retrospective and single-center evaluation of 13,254 patients undergoing MPS. Therefrom, 12,737 $(96.1 \%)$ were $<80$ years and $517(3.9 \%) \geq 80$ years old. When comparing these two groups, octogenarians had more severe and extensive myocardial ischemia, while coronary artery disease (CAD) was more pronounced and diffuse. Like in previous investigations, ${ }^{2-7}$ octogenarians had a significantly higher major adverse cardiac event rate than in younger patients during a mean follow-up period of 32 months. Notably, in the current retrospective analysis, ${ }^{1}$ the diagnostic accuracy of MPS was similar among both groups (area under the curve (AUC) for, e.g., two or three vessel disease: 0.54 vs 0.58 ), while the prognostic accuracy was higher or comparable between octogenarians and the younger group for death (hazard ratio (HR):10.7 vs 2.72), myocardial infarction (HR: 1.06 vs 1.24), or their combination (HR: 4.93 vs 1.87). Such findings accord with other investigations ${ }^{3,7-9}$ that octogenarians are likely to have both elevated incidence and mortality from CAD as compared to the younger population. Despite similar diagnostic and prognostic accuracy of MPS in both groups, coronary revascularization was non-significantly lower in octogenarians $(3.71 \%$ vs

Reprint requests: Thomas H. Schindler, M.D., Division of Nuclear Medicine, Mallinckrodt Institute of Radiology, Washington University School of Medicine, 510 S. Kingshighway, St. Louis, MO 63110; thomas.h.schindler@gmail.com

J Nucl Cardiol 2018;25:1350-2.

1071-3581/ $\$ 34.00$

Copyright (c) 2018 American Society of Nuclear Cardiology.
$6.96 \%, p=0.068)$. This may be seen as a reflection of a balanced clinical decision between revascularization procedures both after coronary artery bypass graft $(\mathrm{CABG})$ and percutaneous coronary intervention (PCI)related elevations in mortality with increasing age and the potential benefit of coronary revascularization for symptoms and outcome. ${ }^{9,10}$ Given the increased mortality risk of coronary revascularization procedures, physicians may tend more to a medical conservative medical treatment approach to relief angina symptoms in first instance before accepting an early albeit minor invasive intervention risk.

These results of Nudi et al., ${ }^{1}$ assessed in a retrospective fashion, contribute to further refine the role of MPS in octogenarians. Given the steady increase of elderly patients or individuals older than 75 years, MPS is likely to play a more central role in these elderly patients for the detection of hemodynamic and prognostic relevant CAD. ${ }^{2}$ Notably, CAD appears to be the prevalent cause of morbidity and mortality in the elderly. ${ }^{11}$ While the increasing use of modern coronary revascularization procedures has indeed reduced cardiovascular morbidity and mortality in younger patients, this was not so much observed for the elderly population. ${ }^{11}$ The reason for this divergent observation remains uncertain but may be related to the clinical challenge to identify CAD in the elderly and advanced age per se. Advanced CAD in the elderly may frequently manifest as silent ischemia, atypical symptoms, and of a nonspecific deterioration of functional capacity. In this direction, Hachamovitch et al. ${ }^{2}$ analyzed the role of MPS in 5220 elderly patients to identify individuals at cardiovascular risk over a mean follow-up of $2.8 \pm 1.7$ years. As regards cardiac deaths, a constant and significantly increase from normal, mildly abnormal, and moderately-to-severely abnormal myocardial perfusion during pharmacologic stress $(1.9 \%$ vs $2.7 \%$ vs $7.8 \%)$ or exercise stress $(0.7 \%$ vs $1.0 \%$ vs $2.7 \%)$ was observed. Similarly, Nudi et al. ${ }^{1}$ demonstrated that the 
extent and severity of myocardial ischemia was also paralleled by a worsened cardiovascular outcome but the current study expands it now to octogenarians in a relatively high numbers of 517 individuals. Thus, current ${ }^{1}$ and previous MPS studies ${ }^{2,3,6,7}$ signify that MPS may indeed be of help in identifying elderly patients, even when exceeding 80 years, at risk for cardiovascular events. In particular, Nudi et al. ${ }^{1}$ could demonstrate with a propensity-matched analysis that the MPS-related diagnostic and prognostic accuracy was similar or even better in octogenarians than in younger patients. This novel observation may be surprising at first sight but is likely to be reconciled with observed more advanced and diffuse CAD on invasive coronary angiography in octogenarians than in the younger population. It is quite possible that the commonly lower exercise capacity in the elderly is not sufficient to cause angina symptoms. This is as at a lower exercise capacity the myocardial oxygen demand may not exceed the oxygen supply by the coronary flow despite the presence of a significant epicardial coronary artery lesion. ${ }^{12,13}$ The commonly lower exercise capacity in the elderly, therefore, may indeed mask the potential hemodynamic significance of an epicardial narrowing and symptoms may only become apparent when CAD lesions have advanced to severely stenosed arteries. A selection bias in the current study ${ }^{1}$ for the octogenarians therefore can be assumed, as most patients referred for MPS were likely quite symptomatic and as they had a high pretest likelihood for the presence of advanced and diffuse stages of the CAD process. ${ }^{14}$

In general, randomized clinical investigations have demonstrated that younger patients with symptomatic $\mathrm{CAD}$ do benefit from coronary revascularization in terms of relief of symptoms and quality of life, while cardiovascular outcome commonly remains unaltered. ${ }^{15}$ In this respect, the Trial of Invasive versus Medical therapy in Elderly patients (TIME) investigated the long-term value of invasive versus medical management of stable but symptomatic CAD in the elderly. ${ }^{16}$ Quality of life and prevention of major adverse cardiac events were evaluated in a prospective and randomized fashion enrolling a total of 282 patients aged $\geq 75$ years from fourteen sites in Switzerland. Comparing invasive versus medical treatment on an intention-to-treat analysis a one-year follow-up, results in these patients were similar in respect of symptoms, quality of life, death $(11.1 \%$ vs $8.1 \%, P=0.28)$ or death and non-fatal infarction (17.0\% vs $19.6 \%, P=0.71)$. Conversely, major adverse cardiac events (MACE: death, non-fatal myocardial infarction, or hospitalization for acute coronary syndrome) were significantly higher for medically versus invasively treated patients $(62.2 \%$ vs $25.5 \% ; P<0.001)$. Overall, this milestone investigation ${ }^{16}$ outlined that medical treatment of angina chest pain may be seen as equivalent to coronary revascularization procedures in order to relief symptoms and to improve quality of life at the expense, however, of $a \approx 50 \%$ possibility of later hospitalization and revascularization. For example, antiangina drugs (e.g., B-blocker, calcium antagonist, longacting nitrates, or potassium blockers) and/or preventive medical therapy (e.g., HMG-CoA reductase or angiotensin-converting enzyme inhibitors) of the CAD process may reduce the metabolic myocardial demand and/or improve the vasodilator capacity of the coronary circulation, which likely results in a reduction or even reversal of clinically manifest myocardial ischemia as demonstrated by a subanalysis of the COURAGE (Clinical Outcomes Utilizing Revascularization and Aggressive Drug Evaluation) trial. ${ }^{17}$ Medical treatment of cardiovascular risk factors in patients with proven ischemia on SPECT perfusion images over a 12-month follow-up period was indeed paralleled by a significant reduction in ischemic burden and a favorable clinical outcome. ${ }^{17}$ Another important endogenous factor that accounts for reduction in ischemic burden and symptoms is the induction of collaterals by the ischemiarelated hypoxic stimulus. ${ }^{13}$

Taken together, the results of Nudi et al. ${ }^{1}$ clearly outline the clinical value of MPS for ischemia detection and prognostication in octogenarians, while it remains to be investigated how adequate optimized anti-angina and/or preventive medical or invasive treatment leads not only to a relief in angina symptoms but also to a reduction in myocardial ischemia associated with an improved cardiovascular outcome in this group of patients also likely to suffer "natural", death in the near future. The study of Nudi et al. ${ }^{1}$ provides another milestone for the clinical use of MPS for treatment justification in octogenarians, while it is likely to stimulate further prospective studies evaluating medical and invasive treatment response with MPS and its effect on the remaining life expectancy in this elderly population.

\section{References}

1. Nudi F, Biondi-Zoccai G, Schillaci O, di Belardino N, Versaci F, Nudi A, et al. Prognostic accuracy of myocardial perfusion imaging in octogenarians. J Nucl Cardiol 2017. https://doi.org/10.1007/s12350-017-1102-x.

2. Hachamovitch R, Kang X, Amanullah AM, Abidov A, Hayes SW, Friedman JD, et al. Prognostic implications of myocardial perfusion single-photon emission computed tomography in the elderly. Circulation 2009;120:2197-206.

3. Curtis JP, Ko DT, Wang Y, Wackers FJ, Foody JM. The prognostic value of vasodilator myocardial perfusion imaging in octogenarians. Am J Geriatr Cardiol 2004;13:239-45.

4. Katsikis A, Theodorakos A, Drosatos A, Konstantinou K, Papaioannou S, Koutelou M. Risk stratification for large artery or 
chronic coronary artery disease-related ischemic stroke in octogenarians undergoing exercise stress myocardial perfusion imaging: a cohort study. J Nucl Cardiol 2017;24:591-5.

5. Katsikis A, Theodorakos A, Papaioannou S, Kalkinis A, Kolovou G, Konstantinou K, et al. Adenosine stress myocardial perfusion imaging in octogenarians: Safety, tolerability, and long-term prognostic implications of hemodynamic response and spect-related variables. J Nucl Cardiol 2017. https://doi.org/10.1007/s12350-017-0893-0.

6. Katsikis A, Theodorakos A, Papaioannou S, Tsapaki V, Kolovou $\mathrm{G}$, Drosatos A, et al. Long-term prognostic value of myocardial perfusion imaging in octogenarians able to undergo treadmill exercise stress testing. J Nucl Cardiol 2014;21:1213-22.

7. Katsikis A, Theodorakos A, Manira V, Papaioannou S, Kolovou $\mathrm{G}$, Voudris $\mathrm{V}$, et al. Long-term prognostic implications of myocardial perfusion imaging in octogenarians: an all-comer, cohort study. Eur J Nucl Med Mol Imaging 2017;44:1547-58.

8. Mozaffarian D, Benjamin EJ, Go AS, Arnett DK, Blaha MJ, Cushman M, American Heart Association Statistics C, Stroke Statistics S., et al. Heart disease and stroke statistics-2015 update: a report from the American Heart Association. Circulation 2015;131:e29-322.

9. Alexander KP, Anstrom KJ, Muhlbaier LH, Grosswald RD, Smith $\mathrm{PK}$, Jones RH, et al. Outcomes of cardiac surgery in patient$\mathrm{s} \geq 80$ years: results from the national cardiovascular network. J Am Coll Cardiol 2000;35:731-8.

10. Batchelor WB, Anstrom KJ, Muhlbaier LH, Grosswald R, Weintraub WS, O'Neill WW, et al. Contemporary outcome trends in the elderly undergoing percutaneous coronary interventions: results in 7472 octogenarians. National cardiovascular network collaboration. J Am Coll Cardiol 2000;36:723-30.
11. Lee PY, Alexander KP, Hammill BG, Pasquali SK, Peterson ED. Representation of elderly persons and women in published randomized trials of acute coronary syndromes. JAMA 2001;286:70813.

12. Schindler TH, Zhang XL, Vincenti G, Lerch R, Schelbert HR. Role of pet in the evaluation and understanding of coronary physiology. J Nucl Cardiol 2007;14:589-603.

13. Schindler TH, Schelbert HR, Quercioli A, Dilsizian V. Cardiac PET imaging for the detection and monitoring of coronary artery disease and microvascular health. JACC Cardiovasc Imaging 2010;3:623-40.

14. Schindler TH. Myocardial blood flow: putting it into clinical perspective. J Nucl Cardiol 2016;23:1056-71.

15. Blumenthal RS, Cohn G, Schulman SP. Medical therapy versus coronary angioplasty in stable coronary artery disease: a critical review of the literature. J Am Coll Cardiol 2000;36:668-73.

16. Pfisterer M, Buser P, Osswald S, Allemann U, Amann W, Angehrn W, Trial of Invasive versus Medical therapy in Elderly patients I, et al. Outcome of elderly patients with chronic symptomatic coronary artery disease with an invasive vs optimized medical treatment strategy: one-year results of the randomized time trial. JAMA 2003;289:1117-23.

17. Shaw LJ, Berman DS, Maron DJ, Mancini GB, Hayes SW, Hartigan PM, et al. Optimal medical therapy with or without percutaneous coronary intervention to reduce ischemic burden: results from the clinical outcomes utilizing revascularization and aggressive drug evaluation (courage) trial nuclear substudy. Circulation 2008;117:1283-91. 